\title{
Cancer health inequality persists in regional and remote Australia
}

\section{High-quality oncology care in rural Australia requires ongoing government commitment}

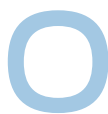

ne in two men and one in three women in Australia will be diagnosed with cancer during their lifetime, with malignant disease accounting for $30 \%$ of all deaths. ${ }^{1}$ Over the past 30 years, cancer incidence has increased by $27 \%$, during which time 5-year survival has improved from $47 \%$ to $66 \%{ }^{2}$

The cost of cancer care has increased rapidly with advances in early diagnosis, surgical techniques, systemic therapy and radiotherapy. However, despite malignancy contributing to over $30 \%$ of mortality, direct cancer health costs comprise only $7 \%$ of the health budget for chronic diseases. ${ }^{3}$

\section{The scale of the rural cancer inequality}

About a third of Australia's population resides in regional and remote areas. ${ }^{4}$ For almost 20 years, the poorer cancer survival with increasing rurality has been well documented. ${ }^{5}$ Proponents of equitable cancer services for rural populations have included the Clinical Oncology Society of Australia and Cancer Council Australia, accompanied by prescient editorials in the MJA.6,7 Over the decade to 2010, the disparity in cancer outcomes between rural and urban patients remained unchanged with $7 \%$ higher mortality, equating to almost 9000 additional rural deaths during this period. ${ }^{8}$ The disparity was greatest with oesophageal cancer and melanoma (where tertiary care is essential to maximise cure), with no evident gap in breast cancer mortality rates.

Despite an improvement in national prostate cancer survival since the 1990s, those living in nonmetropolitan areas continue to have $18 \%-32 \%$ poorer survival. ${ }^{9}$ In Queensland, rectal cancer mortality increase by $6 \%$ for every $100 \mathrm{~km}$ that patients reside from the closest radiotherapy centre. Early breast cancer patients in rural New South Wales are more likely to receive suboptimal curative therapies, with an $84 \%$ higher breast cancer mortality. ${ }^{10}$

Diagnostic delays are common with increasing rurality, due to an undersupply of medical practitioners in these areas. Early detection is also limited by fewer diagnostic facilities such as computed tomography scanning and tissue biopsy services, resulting in an increase in late presentations with de-novo metastatic disease.

Cancer outcomes are particularly poor for Indigenous patients living in regional and remote communities. Cancer is underreported in this group, and death rates are $45 \%$ higher than in the nonIndigenous population. ${ }^{11}$

In 2008, only 27 medical oncologists were located in rural locations, comprising $6 \%$ of the national medical oncologist workforce. A further six medical oncologists attended rural outreach clinics on a part-time basis. ${ }^{12}$
BSc(Med), MBBS, FRA Medical Oncologist

Adam Boyce Medical Oncologist ${ }^{2}$

1 Central West Cancer Service, Orange Health Service, Orange, NSW.

2 Lismore Cancer Care and Haematology Unit, Lismore Base Hospital, Lismore, NSW. peter.fox@ health.nsw.gov.au

doi: 10.5694/mjal4.01217

ancer survival outcomes remain poor in rural areas, especially for cancers requiring complex multidisciplinary care

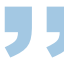

\section{Recent progress}

Significant progress has been achieved in recent years, particularly with the establishment of the regional cancer centre (RCC) initiative announced by the federal government in 2010. Twenty-six RCC projects received total funding of $\$ 694$ million in capital works. ${ }^{13}$

Despite this funding, significant inequalities remain in access to specialist oncology services, especially in areas that are not recipients of RCC funding.

Novel approaches are being increasingly adopted in rural areas to improve both the efficiency and quality of cancer services including telehealth, shared care and surgical oncology networks.

The increasing adoption of telehealth has resulted in improved service provision and substantial cost saving, particularly for remote communities such as Mount Isa. ${ }^{14}$ Telehealth facilities also allow regional sites to link to tertiary metropolitan centres for multidisciplinary team discussion. ${ }^{11}$

Shared care is a common strategy in Canada, and is increasingly being adopted by Australian general practitioners with an interest in cancer therapy, who are integrated with prevention, screening, detection and treatment of cancer. ${ }^{11}$ This is particularly pertinent to remote communities, where the patients are geographically distant to the treating oncologist and are best managed by their primary care physician.

Cancer screening rates in rural Australia have improved in recent years. The trend for prostatespecific antigen screening between 1995 and 2009 has seen a significant improvement in the rural-urban rate ratio from 0.76 to $0.93 .{ }^{15}$ Further, the National Bowel Cancer Screening Program in South Australia has seen higher uptake in regional than metropolitan areas. ${ }^{16}$ However, screening rates remain poor among remote and Indigenous communities, especially for Pap testing, which accounts for substantially higher cervical cancer incidence and mortality in these groups. ${ }^{17}$

Cooperation between state or territory and federal governments is essential to ensure appropriate recurrent funding, which guarantees the long-term sustainability of RCCs. 


\section{The way forward}

High-quality oncology care in rural Australia is a challenge that requires ongoing commitment from state, territory and federal governments. There is no clearly defined staffing profile for a rural oncology unit, and establishing this should be a significant priority. The Clinical Oncology Society of Australia has recommended a staffing and service mix for RCCs, including medical specialists, allied health staff, oncology pharmacists, care coordinators, data managers and clinical trials coordinators (https:// www.cosa.org.au/media/1151/cosa_rr-workshop-2012_ report_final.pdf). Implementing a national standard staffing profile is essential to deliver uniform care throughout rural areas.

Expanding telehealth hardware infrastructure and maintaining Medicare telehealth incentives will ensure the strength of this modality.

In order to assess the effectiveness of initiatives such as shared care, telehealth and care coordinators, data collection is essential. Data collection and management can be improved in rural areas through the adoption of electronic medical records and dedicated data managers to evaluate the success of programs. This will also allow cancer centres to measure the impact of novel pilot programs.

With the expansion of radiation oncology and chemotherapy services under the RCC initiative, many rural patients are no longer required to travel to metropolitan areas for cancer therapy. However, exceptions remain; for example, positron emission tomography scanning and specialised surgery such as cardiothoracic, pancreatic or oesophageal surgery. Further, many patients continue to travel substantial distances to RCCs and are eligible for state and territory government subsidies. State-based road travel subsidies for rural patients are as low as 16 cents per kilometre, ${ }^{18}$ which is significantly below the Australian Tax Office tax-deductible rate of 65 cents per business kilometre. The cost of attending regional or tertiary centres for cancer therapy continues to remain a barrier to improved cancer survival rates.

In conclusion, cancer survival outcomes remain poor in rural areas, especially for cancers requiring complex multidisciplinary care, such as oesophageal cancer. Significant progress has been achieved in recent years with the expansion of RCCs, but ongoing commitment is required at state, territory and federal levels to ensure equitable cancer care for all Australians, regardless of where they reside.

Competing interests: No relevant disclosures.

Provenance: Commissioned; externally peer reviewed.

1 Australian Institute of Health and Welfare, Australasian Association of Cancer Registries. Cancer in Australia: an overview 2012. Canberra: AlHW, 2012. (AlHW Cat. No. CAN 70; Cancer Series No. 74.) http://www.aihw.gov. au/publication-detail/?id=60129542359 (accessed Sep 2014).

2 Australian Institute of Health and Welfare. Cancer survival and prevalence in Australia: period estimates from 1982 to 2010. Canberra: AlHW, 2012. (AlHW Cat. No. CAN 65; Cancer Series No. 69.) http://www.aihw.gov.au/ publication-detail/?id=10737422720 (accessed Sep 2014).

3 Australian Institute of Health and Welfare. Health system expenditure on cancer and other neoplasms in Australia: 2008-09. Canberra: AlHW, 2013.
(AlHW Cat. No. CAN 78; Cancer Series No. 81.) http://www.aihw.gov.au/ publication-detail/?id=60129545611 (accessed Sep 2014).

4 Australian Institute of Health and Welfare. Remoteness classifications. 2013. http://www.aihw.gov.au/rural-health-remoteness-classifications (accessed Aug 2014).

5 Australian Institute of Health and Welfare, Australasian Association of Cancer Registries. Cancer survival in Australia 1992-1997: geographic categories and socioeconomic status. Canberra: AlHW, 2003. (AlHW Cat. No. CAN 17; Cancer Series No. 22.) http://www.aihw.gov.au/publicationdetail/?id=6442467451 (accessed Sep 2014).

6 Jong KE, Vale PJ, Armstrong BK. Rural inequalities in cancer care and outcome [editorial]. Med J Aust 2005; 182: 13-14.

7 Underhill CR, Goldstein D, Grogan PB. Inequity in rural cancer survival in Australia is not an insurmountable problem [editorial]. Med J Aust 2006; 185: 479-480.

8 Coory MD, Ho T, Jordan SJ. Australia is continuing to make progress against cancer, but the regional and remote disadvantage remains. Med J Aust 2013; 199: 605-608.

9 Yu XQ, Luo Q, Smith DP, et al. Geographic variation in prostate cancer survival in New South Wales. Med J Aust 2014; 200: 586-590.

10 Craft PS, Buckingham JM, Dahlstrom JE, et al. Variation in the management of early breast cancer in rural and metropolitan centres: implications for the organisation of rural cancer services. Breast 2010; 19: 396-401.

11 Adams P, Hardwick J, Embree V, et al. Literature review: models of cancer services for rural and remote communities. Sydney: Cancer Institute NSW, 2009. http://www.cancerinstitute.org.au/media/70218/web0983-02_literature_review_models_cancer_services_rural_and_remote communities.pdf (accessed Sep 2014).

12 Blinman PL, Grimison P, Barton MB, et al. The shortage of medical oncologists: the Australian Medical Oncologist Workforce Study. Med J Aust 2012; 196: 58-61.

13 Australian Government Department of Health. Round two: regional cancer centres. 2013. http://www.health.gov.au/internet/main/publishing.nsf/ Content/HHF-RCCPIl (accessed Aug 2014).

14 Thaker DA, Monypenny R, Olver I, Sabesan S. Cost savings from a telemedicine model of care in northern Queensland, Australia. Med J Aust 2013; 199: 414-417.

15 Baade PD, Youlden DR, Coory MD, et al. Urban-rural differences in prostate cancer outcomes in Australia: what has changed? Med J Aust 2011; 194: 293-296.

16 Martini A, Javanparast S, Ward PR, et al. Colorectal cancer screening in rural and remote areas: analysis of the National Bowel Cancer Screening Program data for South Australia. Rural Remote Health 2011; 11: 1648.

17 Australian Institute of Health and Welfare. Cervical screening in Australia 2011-2012. Canberra: AlHW, 2014. (AlHW Cat. No. CAN 79; Cancer Series No. 82.) http://www.aihw.gov.au/publication-detail/?id=60129546865 (accessed Sep 2014).

18 Government of Western Australia, WA Country Health Service. Patient assisted travel scheme. 2011. http://www.wacountry.health.wa.gov.au/ index.php?id=628 (accessed Aug 2014). 